\title{
pH Induced Fabrication of Kaolinite-Chitosan Biocomposite
}

\author{
Shaikat Chandra Dey ${ }^{\mathrm{a}}$, Mohammad Al-Amin ${ }^{\mathrm{b}}$, Taslim Ur Rashid ${ }^{\mathrm{c}}$, \\ Md. Ashaduzzaman ${ }^{\mathrm{d}}$, Sayed Md. Shamsuddin ${ }^{\mathrm{e}^{*}}$ \\ Department of Applied Chemistry and Chemical Engineering, University of Dhaka, \\ Dhaka-1000, Bangladesh \\ E-mail: ashaikatdeydu@gmail.com, bamindu287@gmail.com, 'taslim@du.ac.bd, \\ dazaman01@du.ac.bd \\ ${ }^{*}$ Corresponding Author (E-mail: e sdin@du.ac.bd)
}

Keywords: Indigenous, Biocomposite, Chitosan, Kaolinite, Crystallinity, Morphology.

\begin{abstract}
Functionalization of indigenous materials improves inherent physicochemical properties that depend mainly on their fabrication techniques. Here, $\mathrm{pH}$ triggered biocomposites using different proportions of kaolinite and chitosan were fabricated. It was revealed that the biocomposites were formed in $1 \mathrm{M}$ acetic acid and stabilized after dropwise addition of the mixture of kaolinite and chitosan solution in $3 \mathrm{M} \mathrm{NaOH}$. Binding of kaolinite and chitosan at their interface through functional groups was studied using Fourier transform infrared (FT-IR) spectroscopy and dynamic light scattering (DLS). The average particle size of the biocomposite in aqueous system having $80 \% \mathrm{w} / \mathrm{w}$ kaolinite and $20 \% \mathrm{w} / \mathrm{w}$ chitosan was determined to be $400.8 \mathrm{~nm}$. Crystallinity disappearance of chitosan in the biocomposite, as shown in x-ray diffraction (XRD) spectrum, supports the wrapping of kaolinite with soft and flexible chitosan. Differential scanning calorimetry (DSC) showed the thermal stability of the biocomposites and it was found that the biocomposite fabricated from $50 \% \mathrm{w} / \mathrm{w}$ kaolinite and $50 \% \mathrm{w} / \mathrm{w}$ chitosan was stabled up to $318^{\circ} \mathrm{C}$. Morphological studies were carried out using scanning electron microscopy (SEM), where a progressive tendency towards granular morphology was evidenced with increase in kaolinite content. These functionalized materials in bionanocomposite structure would play a vital role in advanced research in analytical and environmental science.
\end{abstract}

\subsection{Introduction}

Composites, fabricated from petroleum-based synthetic polymers, adversely affect the Earth's ecosystem due to their non-biodegradable nature. There are also limited disposal methods for the persistent plastic wastes which are generated after their respective applications. As a result it is an urgent need to develop eco-friendly green composite materials of natural origin because they don't involve toxic or noxious chemicals for manufacture. At the same time they will be naturally converted into degradation products [1]. Biocomposites add new dimensions to the existing properties of biopolymer and form an interdisciplinary arena combining biology, chemistry and material science together [2]. Biocomposites from waste and naturally occurring materials are promising candidates for numerous industrial applications. In this regard, biopolymer chitosan is an excellent choice because it possesses some special characteristics e.g. it is cheap, available, biocompatible, biodegradable, hydrophilic, non-toxic, it easily undergoes chemical modification, it has good adhesion, ion-exchange and adsorpion properties etc. [3]. However, due to some drawbacks the industrial applications of chitosan are limited. The limitations are: it has a tendency to gel formation and it becomes soft in aqueous media due to hydrophilicity, it has a low specific surface area, it has a low specific gravity, it swells and floats in water, it has weak mechanical properties, higher solubility in acidic media etc. [4-6]. Although, various chitosan based composites have been developed in recent years to overcome these drawbacks, greater attention has been paid to the immobilization of chitosan on clay minerals [7]. Clay minerals can significantly improve the properties of chitosan by providing excellent surface interaction due to its smaller particle size, higher surface area, aspect ratio, better dispersion properties etc. [1]. Besides clay minerals possess some excellent properties such as good biocompatibility, non-toxicity and great prospects for 
controlled release which make grounds for their applications in food, medicine, pharmacy, cosmetics etc. [8]. However, to the best of our knowledge, little attention has been paid to the kaolinite based chitosan biocomposite with a fewer number of scientific publications. Therefore, we were interested in developing an eco-friendly kaolinite-chitosan green biocomposite material.

\subsection{Literature Review}

Different types of solvents have been reported in literature for preparing chitosan based composites. However, major focuses have been given on acetic acid for dissolving chitosan. Table 1 distinguishes various chitosan based biocomposites based on different solvent systems.

Table 1: Various solvents used for chitosan based composites

\begin{tabular}{l|l}
\hline \multicolumn{1}{c|}{ Solvent } & \multicolumn{1}{c}{ Composite Type } \\
\hline Acetic Acid & $\begin{array}{l}\text { Chitosan-montmorrilonite [9-15], Chitosan-activated clay [16], } \\
\text { Chitosan-oil palm ash [17], Crosslinked chitosan-coated } \\
\text { bentonite [18], Chitosan/kaolin/ } \gamma-\mathrm{Fe}_{2} \mathrm{O}_{3} \text { [19], Chitosan-ball } \\
\text { clay [20], Chitosan/Feldspar [21], Chitosan/rectorite [22] }\end{array}$ \\
Oxalic Acid & $\begin{array}{l}\text { Chitosan-ceramic alumina [23, 24], Chitosan-activated ceramic } \\
\text { alumina [25], Chitosan-perlite [26-28] }\end{array}$ \\
Hydrochloric Acid & $\begin{array}{l}\text { Chitosan-sand [29, 30], Chitosan-coated kaolinite [31] } \\
\text { Chitosan-kaolin clay [32] }\end{array}$ \\
\hline
\end{tabular}

Kanchana, Gomathi et al. 2012, prepared binary composites of nanochitosan-kaolin clay and nanochitosan-methylcellulose using formic acid [32]. Zhu, Jiang et al. 2010, prepared a ternary composite of chitosan/kaolin/nanosized $\gamma-\mathrm{Fe}_{2} \mathrm{O}_{3}$ using acetic acid [19]. Both of these studies utilized glutaraldehyde as cross-linking agent. Chen, Kan et al. 2015 prepared chitosan-coated kaolinite beads using hydrochloric acid without any cross-linking agent [31]. A number of methods have been widely used for the fabrication of composite materials e.g. pultrusion, wet lay-up, autoclave processing, prepreg method, resin transfer molding, vacuum assisted resin transfer molding, resin film infusion, filament winding, fiber placement technology, template synthesis, intercalation of polymer, in-situ intercalative polymerization, melt intercalation etc. [33, 34].

\subsection{Vision of the Study}

The major objectives of this study are: preparing kaolinite-chitosan bicomposites using acetic acid without any cross-linking agent, thoroughly investigating the effect of solution $\mathrm{pH}$ on the composite fabrication process, preparing composite via simple dispersion method and characterizing the prepared composite.

\section{Materials and Methods}

\subsection{Materials}

Kaolinite clay and waste prawn shells were collected from local source of Bangladesh. Purified sodium hydroxide pellets and hydrochloric acid (35\%) were supplied by Active Fine Chemicals Limited, Dhaka, Bangladesh. Anhydrous glacial acetic acid (100\%) was purchased from Merck KGaA (64271 Darmstadt, Germany).

\subsection{Preparation of chitosan from waste prawn shells}

A four steps process was followed for the preparation of chitosan from waste prawn shells. The process comprised of washing, deproteination, demineralization and deacetylation. The product chitosan was tested by its solubility in $1 \%(\mathrm{v} / \mathrm{v})$ acetic acid [35].

\subsection{Purification and activation of kaolinite}

The raw clay was first mixed with distilled water and the suspension was passed through 325 mesh screen $(45 \mu)$ to separate larger particles. The underflow was filtered and the cake was dried in the oven at $60^{\circ} \mathrm{C}$ for 10 hours. The dried cake was then ground with a mortar and pestle. The purified clay was treated with $2 \mathrm{M}$ hydrochloric acid at room temperature of $25^{\circ} \mathrm{C}$ for 48 hours at $150 \mathrm{rpm}$ using a mechanical shaker to remove the free quartz. Higher content of quartz may decrease the 
performance of the composites. The clay was separated by centrifugation and washed several times to remove residual acid. The acid activated kaolinite was dried in the oven at $60^{\circ} \mathrm{C}$ for 10 hours.

\subsection{Preparation of Biocomposites}

Chitosan flakes were dissolved in $100 \mathrm{~mL} 1 \mathrm{M}$ acetic acid and kaolinite was then added to the chitosan solution. The resulting mixture was agitated by a sonicator for 30 minutes. The mixture was then sprayed drop wise into a neutralization solution of $15 \% \mathrm{NaOH}$ and $95 \%$ ethanol in a volume ratio of $4: 1$. The formed composite beads were washed several times and dried in the oven at $60^{\circ} \mathrm{C}$ for 10 hours. The beads, after drying, were ground to reduce their particle size [16]. A simplified scheme along with core-shell structure of biocomposite is clearly depicted in Fig. 1.

\subsection{Characterization techniques used}

FT-IR spectra of the samples were recorded by a FT-IR 8400S spectrophotometer (Shimadzu Corporation, Japan) in the wavenumber range of $4000-400 \mathrm{~cm}^{-1}$. XRD patterns of the samples were recorded by an x-ray diffractometer (Ultima IV, Rigaku Corporation, Japan) at room temperature. $\mathrm{Cu} \mathrm{K \alpha}$ radiation $(\lambda=0.154 \mathrm{~nm})$, from a broad focus $\mathrm{Cu}$ tube operated at $40 \mathrm{kV}$ and $40 \mathrm{~mA}$, was applied to the samples for measurement. The thermal degradation profiles of the samples up to $400^{\circ} \mathrm{C}$ were recorded by a differential scanning calorimeter (DSC-60 Shimadzu, Japan). Hydrodynamic diameters of the samples were measured by Zetasizer Nano ZS90 (ZEN3690, Malvern Instruments Ltd, UK) by dynamic light scattering method (DLS). As a light source, He-Ne laser of $632.8 \mathrm{~nm}$ wavelength was used. SEM images of samples were recorded by an analytical scanning electron microscope (JEOL JSM-6490LA, Tokyo, Japan) operated at an accelerating voltage of $20 \mathrm{kV}$ in the back-scattered electron mode.

\section{Results and Discussion}

Various parameters may have direct impact on the clay/polymer interactions such as size and shape of clay particles, its surface charge, concentration of clay and polymer, molecular weight of polymers, hydrolyzing groups of polymers, temperature, $\mathrm{pH}$ etc. [36]. Considering the above facts we have closely monitored the effect of $\mathrm{pH}$ on the composite fabrication process.

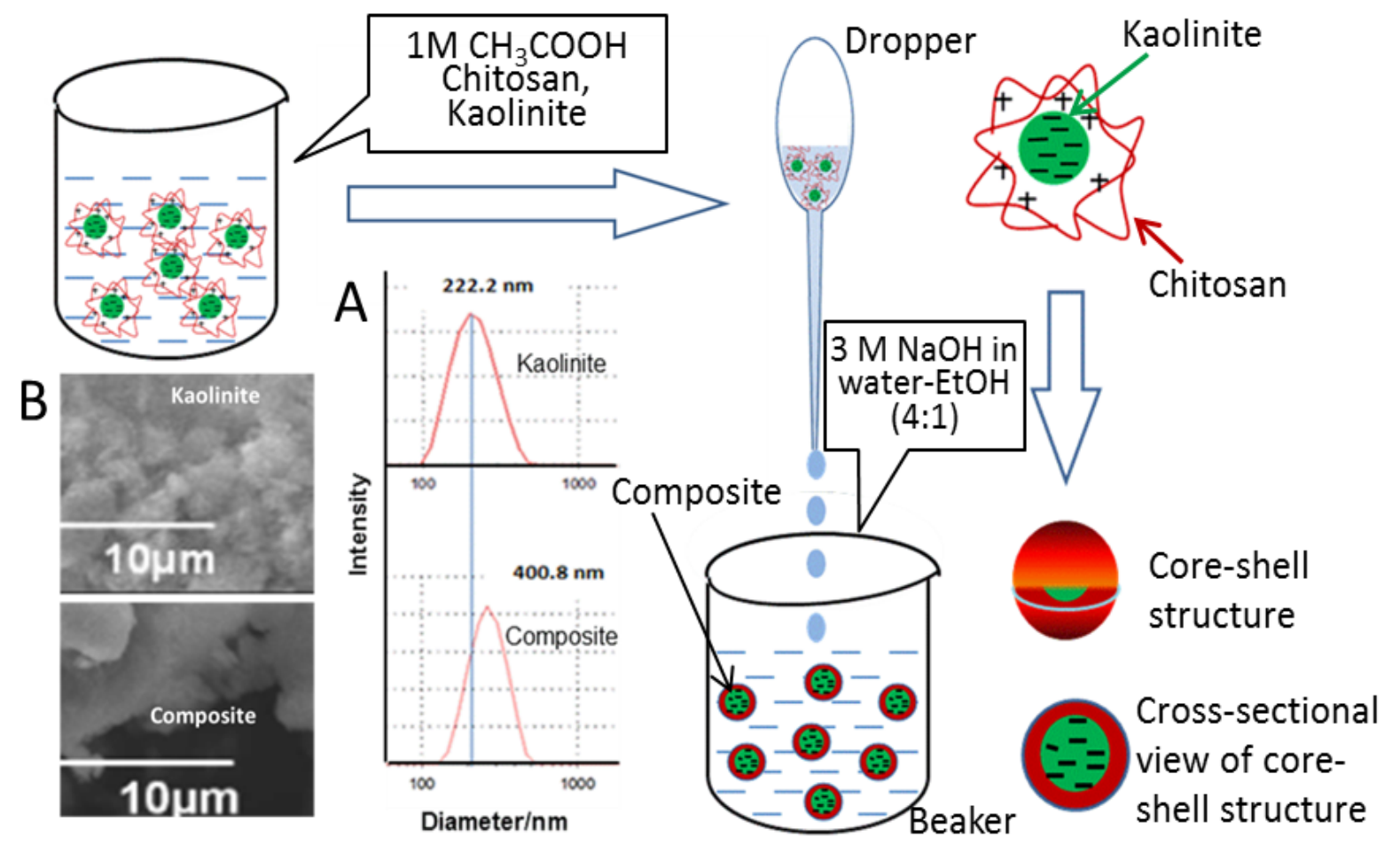

Fig. 1: Simplified scheme for biocomposite preparation (A: DLS images; B: SEM images). 
Solution $\mathrm{pH}$ played a vital role in the fabrication of the composites. Suspension of kaolinite in chitosan solution was centrifuged at $3000 \mathrm{rpm}$ for 10 minutes. We closely monitored that kaolinite particles were separated due to the centrifugal motion. So, the interaction of kaolinite with chitosan was not stable in acidic media. Dropwise addition of the suspension in alkaline media resulted in bead formation of the composites. The rapid neutralization of the acetic acid helped the retention of the spherical shape of the beads [26]. The beads were stable in nature and kaolinite lost its individual identity due to bead formation. We further centrifuged the mixture containing the beads. This time kaolinite couldn't separate itself from the beads. Therefore, this study confirmed the $\mathrm{pH}$ dependent nature of the biocomposite fabrication process.

\subsection{Fourier transform infrared spectroscopy (FT-IR)}

In the spectrum of chitosan, as shown in Fig. 2, the absorption band at $1635.64 \mathrm{~cm}^{-1}$ is assigned to the in-plane N-H bending vibration of the polysaccharide [37]. The peak at $1631.78 \mathrm{~cm}^{-1}$ in case of kaolinite is assigned to the $\mathrm{H}-\mathrm{O}-\mathrm{H}$ bending vibration due to adsorbed water [38]. The spectrum of composite showed the combination of characteristic absorption bands due to kaolinite and chitosan. From the figure it is clear that the absorption band of chitosan at $1635.64 \mathrm{~cm}^{-1}$ was shifted to $1624.06 \mathrm{~cm}^{-1}$ in composite. This shift occurred due to the electrostatic interaction between the protonated amine groups $\left(\mathrm{NH}_{3}{ }^{+}\right)$of chitosan and negatively charged sites of kaolinite. In order to make it confirm whether it was actually a composite or just a clay-chitosan physical mixture, 100 $\mathrm{mg}$ of kaolinite and $100 \mathrm{mg}$ of chitosan was ground using mortar-pestle. FT-IR spectrum of finely ground kaolinite-chitosan physical mixture was taken. No significant shift in the absorption band $\left(1633.71 \mathrm{~cm}^{-1}\right)$ was found for the physical mixture which confirmed that the composite prepared by dispersion method was actually a composite, not a physical mixture.

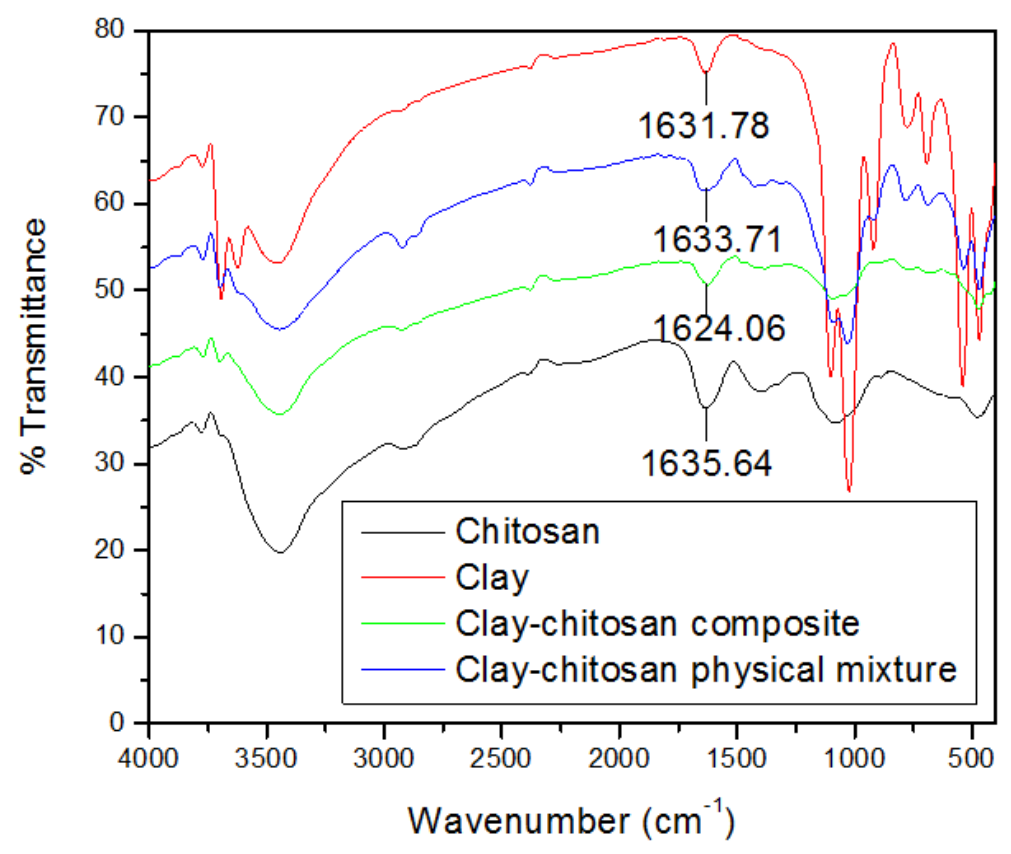

Fig. 2: FT-IR spectra of chitosan, clay, clay-chitosan composite and physical mixture.

\subsection{X-ray Diffraction (XRD)}

XRD patterns of raw and acid treated clay showed significant differences as shown in Fig. 3(A). The raw clay exhibited well-defined reflections at $2 \theta$ around $12.365(\mathrm{~d}=7.152 \AA)$ and $24.932^{\circ}(\mathrm{d}=$ $3.5684 \AA$ ). These two peaks are assigned as characteristic peaks of kaolinite [32]. Clay also showed reflection at higher $2 \theta$ values from different crystallographic planes. The figure also revealed the presence of free quartz phases. Among various quartz phases the most prominent one was obtained at $2 \theta=26.68^{\circ}(\mathrm{d}=3.3385 \AA)[39]$. 

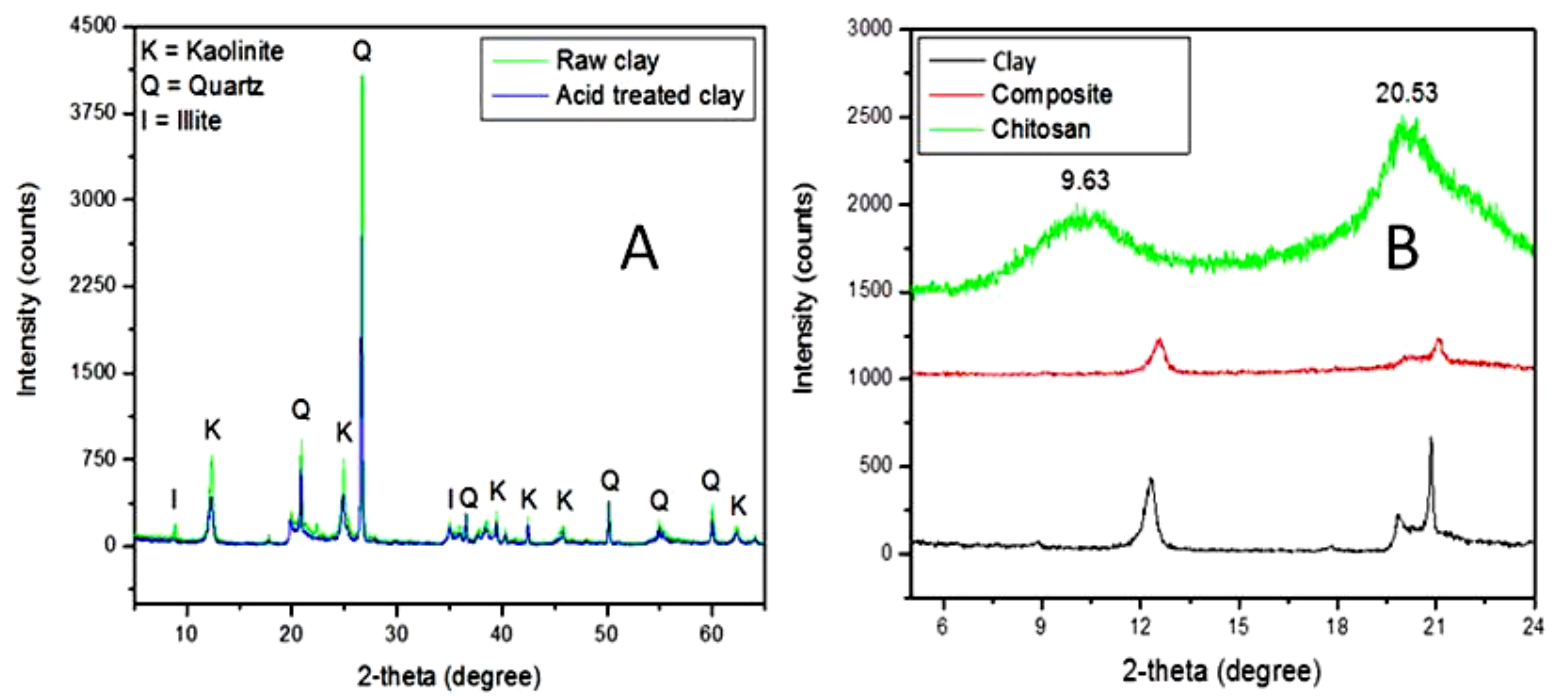

Fig. 3: XRD patterns of (A) raw and acid treated clay; (B) clay, chitosan and composite.

From the figure it is evident that the quartz phase was highly affected by acid treatment because the intensity of quartz phase was reduced to a significant extent [40]. Although the kaolinite phases were not strongly affected by acid treatment, the lowering of the intensity of the peaks was attributed to the structural disorder [41]. Therefore, it can be concluded that quartz can't be completely eliminated by $2 \mathrm{M} \mathrm{HCl}$, but its amount can be lowered to a significant extent. It can also be said that it would not be logical to use higher concentration of $\mathrm{HCl}$ because highly concentrated acid will cause structural disorder of kaolinite. The XRD pattern of chitosan, as depicted in Fig. 3(B), showed broad diffraction peaks at $2 \theta$ around 9.63 and 20.53 corresponding to the typical fingerprints of semi-crystalline chitosan [42]. These two peaks attribute a high degree of crystallinity to chitosan and are assigned to the crystal I and crystal II in chitosan structure [36, 43]. From the figure, it is clear that the crystallinity of chitosan was disappeared in composite as two sharp peaks of chitosan at $2 \theta=9.63$ and $2 \theta=20.53$ are absent in composite.

\subsection{Differential scanning calorimetry (DSC)}

As shown in Fig. 4, there was a clear distinction in the DSC thermograms of chitosan, kaolinite and composite. Chitosan showed the exothermic degradation peak between $303.77-304.28^{\circ} \mathrm{C}$ whereas composite showed the degradation peak between $318.51-319.39^{\circ} \mathrm{C}$ i.e. the degradation of chitosan was delayed in the composite due to its chemical attachment with kaolinite. Therefore, the thermal stability of chitosan was improved due to composite formation.

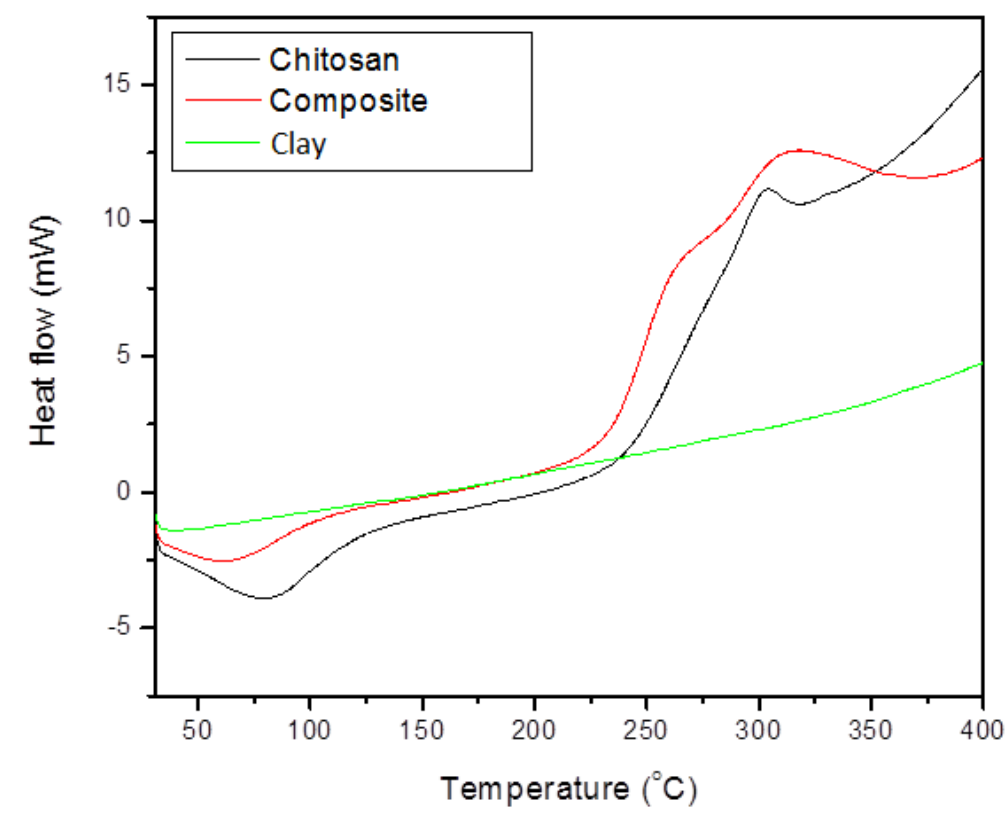

Fig. 4: DSC thermograms of chitosan, clay and composite. 
The enhanced thermal stability of the biocomposite is attributed to the changes in dynamics of molecular motion introduced by the addition of clay minerals [44]. Clay platelets create a tortuous pathway for the volatile decomposition products out of the biocomposite bulk thereby increasing the effective path length for diffusion. As a result the rate of diffusion is reduced [45].

\subsection{Dynamic light scattering (DLS)}

The hydrodynamic diameter of kaolinite was found to be $222.2 \mathrm{~nm}$ as indicated in Fig. 1(A). Since DLS measure the hydrodynamic diameter, the actual particle size was smaller than $222.2 \mathrm{~nm}$. Therefore, from the DLS study it can be confirmed that kaolinite utilized in this study is a nanoscale material. The hydrodynamic diameter of the composite was found to be $400.8 \mathrm{~nm}$. The enhancement of hydrodynamic diameter of composite was due to the attachment of chitosan polymer with kaolinite particles in the form of composite. So there was some molecular interaction at the bio-nano surface of the composites. Therefore, we can conclude that the prepared composite was actually a bio-nanocomposite. The enhancement of hydrodynamic diameter from kaolinite to composite clearly indicates that hard kaolinite was wrapped with soft chitosan. This type of wrapping results in core-shell structure of the biocomposite having kaolinite in the core and chitosan as shell (Fig. 1).

\subsection{Scanning electron microscopy (SEM)}

Fig. 1(B) indicates that the morphological features of the biocomposite are clearly distinct from that of kaolinite. Kaolinite showed fragmented particle nature whereas a uniform granular morphology developed in case of the biocomposite. This uniform granular morphology is highly desirable for its industrial applications as the uniform and spherical surface will certainly show better properties than the kaolinite or chitosan alone.

\section{Conclusions}

In this present study, biocomposites from waste and naturally occurring indigenous materials were successfully prepared and characterized. The incorporation of kaolinite improved the thermal properties of chitosan and the crystallinity of chitosan disappeared in biocomposites. Kaolinte contains a net negative charge on its surface and chitosan shows polycationic nature in acidic media. As a result there is a versatile charge distribution on the surface of the bicomposites. The smaller particle size, larger surface area, numerous active sites on the surface, availability of raw materials and cost-effective nature of preparation have made these biocomposites potential candidate for numerous industrial applications in leather, textile, food, pharmaceuticals etc.

\section{Acknowledgements}

The authors are grateful to the Ministry of Science and Technology, Government of the People's Republic of Bangladesh for providing partial financial support as National Science and Technology (NST) Fellowship. We are also thankful to the Centre for Advanced Research in Sciences (CARS), University of Dhaka, Dhaka-1000, Bangladesh, for providing partial analytical support. 


\section{References}

[1] M. Okamoto, Biodegradable polymer/layered silicate nanocomposites: a review, Journal of Industrial and Engineering Chemistry, 10 (2004) 1156-1181.

[2] R.A. Hule and D. J. Pochan, Polymer nanocomposites for biomedical applications, Mrs Bulletin, 32 (2007) 354-358.

[3] M.N.R. Kumar, A review of chitin and chitosan applications, Reactive and functional polymers, 46 (2000) 1-27.

[4] S.R. Popuri, Y. Vijaya, V.M. Boddu and K. Abburi, Adsorptive removal of copper and nickel ions from water using chitosan coated PVC beads, Bioresource Technology, 100 (2009) 194199.

[5] S. Hasan, T.K. Ghosh, D.S. Viswanath and V.M. Boddu, Dispersion of chitosan on perlite for enhancement of copper (II) adsorption capacity, Journal of Hazardous Materials, 152 (2008) 826-837.

[6] M.-S. Chiou and H.-Y. Li, Equilibrium and kinetic modeling of adsorption of reactive dye on cross-linked chitosan beads, Journal of Hazardous materials, 93 (2002) 233-248.

[7] W.W. Ngah, L.Teong and M. Hanafiah, Adsorption of dyes and heavy metal ions by chitosan composites: A review, Carbohydrate Polymers, 83 (2011) 1446-1456.

[8] C.-M. Hristodor, N. Vrinceanu, A. Pui, O. Novac, V.-E. Copcia and E. Popovici, Textural and Morphological Characterization of Chitosan/Bentonite Nanocomposite, Environmental Engineering and Management Journal, 11 (2012) 573-578.

[9] D. Fan, X. Zhu, M. Xu and J. Yan, Adsorption properties of chromium (VI) by chitosan coated montmorillonite, Journal of Biological Sciences, 6 (2006) 941-945.

[10] H. Gecol, P. Miakatsindila, E. Ergican and S.R. Hiibel, Biopolymer coated clay particles for the adsorption of tungsten from water, Desalination, 197 (2006) 165-178.

[11] L. Wang and A. Wang, Adsorption characteristics of Congo Red onto the chitosan/montmorillonite nanocomposite, Journal of Hazardous Materials, 147 (2007) 979985.

[12] P. Monvisade and P. Siriphannon, Chitosan intercalated montmorillonite: Preparation, characterization and cationic dye adsorption, Applied Clay Science, 42 (2009) 427-431.

[13] A. Anjum, C.K. Seth and M. Datta, Characterization of Montmorillonite Biocomposite and Its Application for Trace Level Removal of $\mathrm{Sb}^{3+}$ : Equilibrium and Kinetic Studies, International Journal of Chemistry, 7 (2015) 28.

[14] A. Shehap, A. Bakr and O. T. Hussein, Characterization of Clay/Chitosan Nanocomposites and their Use for Adsorption On Mn (II) from Aqueous Solution, International Journal of Science and Engineering Applications, 4 (2015).

[15] A. Anjum, C. Seth and M. Datta, Removal of $\mathrm{As}^{3+}$ using chitosan-montmorillonite composite: sorptive equilibrium and kinetics, Adsorption Science \& Technology, 31 (2013) 303-324.

[16] M.-Y. Chang and R.-S. Juang, Adsorption of tannic acid, humic acid, and dyes from water using the composite of chitosan and activated clay, Journal of Colloid and Interface Science, 278 (2004) 18-25.

[17] M. Hasan, A. Ahmad and B. Hameed, Adsorption of reactive dye onto cross-linked chitosan/oil palm ash composite beads, Chemical Engineering Journal, 136 (2008) 164-172.

[18] W.S.W. Ngah, N.F.M. Ariff and M.A.K.M. Hanafiah, Preparation, characterization, and environmental application of crosslinked chitosan-coated bentonite for tartrazine adsorption from aqueous solutions, Water, Air, and Soil Pollution, 206 (2010) 225-236.

[19] H.-Y. Zhu, R. Jiang and L. Xiao, Adsorption of an anionic azo dye by chitosan $/ \mathrm{kaolin} / \gamma-\mathrm{Fe}_{2} \mathrm{O}_{3}$ composites, Applied Clay Science, 48 (2010) 522-526.

[20] M. Auta and B. Hameed, Chitosan-clay composite as highly effective and low-cost adsorbent for batch and fixed-bed adsorption of methylene blue, Chemical Engineering Journal, 237 (2014) 352-361. 
[21] M. Yazdani, H. Bahrami and M. Arami, Preparation and Characterization of Chitosan/Feldspar Biohybrid as an Adsorbent: Optimization of Adsorption Process via Response Surface Modeling, The Scientific World Journal, (2014).

[22] S. Li, P. Zhou and L. Ding, Adsorption Application for Removal of Hazardous Chloroform from Aqueous Solution by Nanocomposites Rectorite/Chitosan Adsorbent, Journal of Water Resource and Protection, 3 (2011) 448.

[23] V.M. Boddu, K. Abburi, J.L. Talbott and E.D. Smith, Removal of hexavalent chromium from wastewater using a new composite chitosan biosorbent, Environmental science \& technology, 37 (2003) 4449-4456.

[24] V.M. Boddu, K. Abburi, A.J. Randolph and E.D. Smith, Removal of copper (II) and nickel (II) ions from aqueous solutions by a composite chitosan biosorbent, Separation science and technology, 43 (2008) 1365-1381.

[25] V.M. Boddu, K. Abburi, J.L. Talbott, E.D. Smith and R. Haasch, Removal of arsenic (III) and arsenic (V) from aqueous medium using chitosan-coated biosorbent, Water research, 42 (2008) 633-642.

[26] S. Hasan, A. Krishnaiah, T.K. Ghosh, D.S. Viswanath, V.M. Boddu and E.D. Smith, Adsorption of Chromium (VI) on Chitosan-Coated Perlite, Separation science and technology, 38 (2003) 3775-3793.

[27] S. Hasan, A. Krishnaiah, T.K. Ghosh, D.S. Viswanath, V.M. Boddu and E.D. Smith, Adsorption of divalent cadmium (Cd (II)) from aqueous solutions onto chitosan-coated perlite beads, Industrial \& engineering chemistry research, 45 (2006) 5066-5077.

[28] S. Kalyani, J.A. Priya, P.S. Rao and A. Krishnaiah, Removal of copper and nickel from aqueous solutions using chitosan coated on perlite as biosorbent, Separation Science and Technology, 40 (2005) 1483-1495.

[29] M.-W. Wan, C.-C. Kan, C.-H. Lin, B. D. Rogel and C.-H. Wu, Adsorption of copper ( II ) by chitosan immobilized on sand, Chia-Nan, Annual Bulletin, 33 (2007) 96-106.

[30] M.-W. Wan, C.-C. Kan, B.D. Rogel and M.L.P. Dalida, Adsorption of copper (II) and lead (II) ions from aqueous solution on chitosan-coated sand, Carbohydrate Polymers, 80 (2010) 891-899.

[31] I.-P. Chen, C.-C. Kan, C.M. Futalan, M.J.C. Calagui, S.-S. Lin, W.C. Tsai, et al., Batch and fixed bed studies: Removal of copper (II) using chitosan-coated kaolinite beads from aqueous solution, Sustainable Environment Research, 25 (2015) 73-81.

[32] V. Kanchana, T. Gomathi, V. Geetha and P. Sudha, Adsorption analysis of Pb (II) by nanocomposites of chitosan with methyl cellulose and clay, Pharm. Lett, 4 (2012) 1071-1079.

[33] S. Mazumdar, Composites manufacturing: materials, product, and process engineering: $\mathrm{CrC}$ press, (2001).

[34] M. Alexandre and P. Dubois, Polymer-layered silicate nanocomposites: preparation, properties and uses of a new class of materials, Materials Science and Engineering: R: Reports, 28 (2000) 1-63.

[35] S.C. Dey, M. Al-Amin, T.U. Rashid, M.Z. Sultan et at., Preparation, Characterization and Performance Evaluation of Chitosan as an Adsorbent for Remazol Red, International Journal of Latest Research in Engineering and Technology, 2 (2016) 52-62.

[36] E. Günister, D. Pestreli, C. H. Ünlü, O. Atıcı and N. Güngör, Synthesis and characterization of chitosan-MMT biocomposite systems, Carbohydrate Polymers, 67 (2007) 358-365.

[37] V. Mohanasrinivasan, M. Mishra, J. S. Paliwal, S. K. Singh, E. Selvarajan, V. Suganthi, et al., Studies on heavy metal removal efficiency and antibacterial activity of chitosan prepared from shrimp shell waste, 3 Biotech, 4 (2014) 167-175.

[38] B. J. Saikia and G. Parthasarathy, Fourier transform infrared spectroscopic characterization of kaolinite from Assam and Meghalaya, Northeastern India, Journal of Modern Physics, 1 (2010) 206.

[39] E. Kłosek-Wawrzyn, J. Małolepszy and P. Murzyn, Sintering behavior of kaolin with calcite, Procedia Engineering, 57 (2013) 572-582. 
[40] A.R.d. Nascimento, J.A.B.L.R. Alves, M.A.d.F. Melo, D.M.d.A. Melo, M.J.B.d. Souza and A.M.G. Pedrosa, Effect of the Acid Treatment of Montmorillonite Clay in the Oleic Acid Esterification Reaction, Materials Research, 18 (2015) 283-287.

[41] S. Kumar, A. K. Panda and R. Singh, Preparation and characterization of acid and alkaline treated kaolin clay, Bulletin of Chemical Reaction Engineering \& Catalysis, 8 (2013) 61-69.

[42] C. Bangyekan, D. Aht-Ong and K. Srikulkit, Preparation and properties evaluation of chitosan-coated cassava starch films, Carbohydrate Polymers, 63 (2006) 61-71.

[43] N.M. Julkapli and H.M. Akil, X-Ray Powder Diffraction (XRD) Studies on Kenaf Dust Filled Chitosan Bio-composites, Neutron and X-ray Scattering 2007: The International Conference, (2008) 111-114.

[44] A. Leszczynska and K. Pielichowski, Application of thermal analysis methods for characterization of polymer/montmorillonite nanocomposites, Journal of Thermal Analysis and Calorimetry, 93 (2008) 677-687.

[45] G. Chen, S. Liu, S. Chen and Z. Qi, FTIR spectra, thermal properties, and dispersibility of a polystyrene/montmorillonite nanocomposite, Macromolecular Chemistry and Physics, 202 (2001) 1189-1193. 